\title{
THE CHALLENGES OF ASIAN DISTANCE EDUCATIONAL DEVELOPMENT
}

\author{
Jack Fei Yang (yang@mail.hku.edu.tw) \\ Hsing-Kao University, Taiwan ROC
}

\begin{abstract}
Distance education systems make global educational more accessible for an increasing number of students. Distance education, which offers the conveniences of flexible time and place for study, can allow many students from different societies and cultures-regardless of race, gender, age, and nationality differences-to have equal opportunities. Nevertheless, there are still many challenges and limitations that a global distance education system has to overcome. The discussion in this paper is focused on differences between the East and the West. The writer suggests that primary issues to consider in order to develop a global distance learning system are: assuring consistent educational quality, gaining confidence in social perceptions, accommodating diverse learning/teaching styles, and creative approaches to accommodating language differences.
\end{abstract}

Key words: Distance Education, Distance Educational Challenges, Learning Style

Distance education systems make the goal of international education systems become more achievable and more accessible to all students. The main advantages of distance education are that it doesn't require physical attendance or a rigid schedule. This allows students from different societies, cultures, and nations, regardless of their race, gender, age, or nationality, to have equal opportunity to access the educational resource. There are, however, still some challenges and limitations the international distance education system has to overcome, such as language and tuition issues.

Distance educational literature generally concludes that distance educational systems can provide as good an educational quality and learning achievement as traditional education. It is important for the Asian society to develop a good distance educational system in order to provide more resources that are educational and to practice the vision of life-long learning. However, since most distance educational literature is researched by western researchers and is surveyed by the western population, it is doubtful that prior distance educational research results will be suitable for an Asian educational society. Distance education is, therefore, defined as student-centered.

In Asia, the student learning style is teacher-centered because of the traditional Asian cultural social hierarchy. Asian students are stereotypically quiet, docile, and hard working. They are good at following directions but are limited in their creativity. Since the Western counties are currently leading distance-education development and already have the suggested research and literature for future development, it is important for Asian societies to reexamine its educational system, culture and environment, developing its own distance learning system that fits Asian learners. In this research, the author summarized current distance educational trends and analyzed distance-learning 
challenges to Asian learners. This research also developed educational strategies for future distance educational development in Asia.

It is possible for the Asian distance educational system to continue using a teacher-centered distance teaching system if the research and educational system agree that this it is the best approach for Asian students. However, if the Asian distance educational system learns from a Western distance education experience and from literature, making a transition toward the learning and teaching style from teacher-centered to student-centered, it will be an important advancement and improvement for a future international distance educational cooperation.

A successful leadership will guide the organization and the global learning community it serves toward their shared goals. As Crosby (1999) mentioned, "leaders in the global commons create and communicate widely shared visions that inspire and unify many people beyond their own organizations." (p. 107).

It is important for educators to be aware of the economic, political, cultural, and educational concept differences that influence educational system development. The purpose of education in different societies should be the same - education to all. Distance education is playing an important role in providing more educational resources and opportunities anytime, anywhere, for everyone. Instead of serving a general or typical population, in the future distance education should be more focused on developing higher quality and standards of educational development. Distance education is not just a cheap, accessible, second-level educational resource; the quality of distance education should not only fulfill the mission of educational equity but also satisfy the desire of life-long learning.

\section{LEARNING STYLE}

The concept of a learner-controlled educational system is foreign to many educators both East and West. Educational institutions have age-old traditions of teacher-centered methods and student passive learning. Learning through listening and reading has been the norm for centuries. If the full benefits of learning through electronic conversation dialogue, let alone the possibility of full-motion interactive video, are to be realized, then the teaching and learning traditions of the past will have to be modified.

A complex and mature culture (such as in nations of Asia) effects an organization in the areas of values, motivation, training, decision marking, leadership, management, or policy-making. Yukl (2002) stated that different cultural values and traditions can influence the attitudes, behavior and decision-making of leaders in many ways. These differences influence educational policy developments and applications. There is a need for global educators is to study, understand, and be aware of these differences. They penetrate debates on the development, challenges, and goals for building a future global learning society and efforts to promote quality educational systems opportunities to serve to improve access to education for all.

\section{TEACHER-CENTERED AND STUDENT-CENTERED DIFFERENCES EAST AND WEST}

In Western society, the learner-centered teaching method is widely applied in both traditional education and distance education (Egan \& Gibb, 1997). As Peterson (1997) stated, "Higher education has changed from a teacher-centered focus to a learner-centered focus" (p.327). The concept of 
student-centered teaching method has become so important because the level of interaction between teachers and students in high-end-technology distance education is greater than in traditional lecture classrooms. Student-centered teaching approaches require more dialogue and more flexible teaching methods. When the sage on the stage becomes the person on listening on email, the strategies for teaching need to change.

Traditional Asian education has a teacher-centered and competitive learning environment. The teacher is a symbol of authority, power, and knowledge. In old Chinese society, education is a privilege for people to gain political or religious power. Education has been a channel to control people (Chou, 2001). The function of education has been also a symbol of social status more than for knowledge competence through learning and exchange (Wu, 2000). Traditional cultural values indicate that it is not allowed to challenge or to question the teacher's knowledge or behavior. Because students respect the teacher very much, it is hard to imagine that the student and teacher can become friends or establishing a life-time mentoring relationship. This traditional stereotype of Asian education maintains an invisible line between students and teacher that cannot be crossed.

Other factors also create distance between the teacher and student. These may include age, gender, ethics, social status and levels of students' experiences. However, Asian adult learners studying in the West have been confronted with learner-centered teaching and have had to adjust. It is possible to adopt a student-centered approach with Asian traditional learners if instructors make their goals very clear and if teaching approaches give learners increased confidence that they may change their learning norms. Asian adult learners respond to the following issues:

1. Age: Asian adult learners older than the instructor may allow a reduction in the distance between instructor and adult learner.

2. Experience: Asian adult learners with specific levels of knowledge and life experience may create more interaction with teachers.

3. Social status: Asian adult learners with specific levels of career achievement and titles may riskinteracting with teachers as peers and thereby increase the level of interaction between instructor and learner.

\section{DISTANCE EDUCATIONAL CHALLENGES}

Current distance educational theory in the literature includes some general principles that need to be followed in order to develop effective distance educational courses, programs, and systems. Moore and Kearsley (1996) pointed out that the following variables could help educators to determine the effectiveness of distance education courses: (a) student numbers, (b) course length, (c) learner educational backgrounds, (d) instructional strategies and methods, (e) type of learning activities, (f) type of learning pace, (g) type of interaction, (h) involvement level of tutors or facilitators, (i) level of instructor and administrator preparation, and (j) level of learning support.

Berge (1998) mentioned that there are many barriers to online education: (a) faceless teaching, (b) high cost of materials, (c) lack of national agenda and policy leadership, (d) resistance to change, (e) diffusion of value traditionally placed on getting a degree, (e) and faculty culture.

Many variables challenge distance education's effectiveness in different ways; Challenges for global distance education are likely to be even more complex and broad. Issues include matters that are 
political, economic, social, physical, and technological-all impacting quality distance educational developments significantly (Jones Shoemaker, 1998).

Asian society began distance educational development in 1980, compared to nearly a century of distance education history in the West. The Asian distance educational system still has many challenges and difficulties that need to be overcome. Since Asian societies have their own educational philosophies, principles, teaching strategies, learning styles, and educational systems, many educational issues vary somewhat from those in the West. It is a challenge for Asians to accommodate the different and conflicting distance educational principles from the West. Primary is the difference between teacher-centered and learner-centered educational concepts and traditions.

Identifying cultural and educational differences will help new distance educators to develop an appropriate distance educational system to fit each society; moreover, it could also help educators to develop more flexible distance educational systems that can fit each learner's needs.

\section{SEVEN CHALLENGES FOR FUTURE GLOBAL DISTANCE EDUCATIONAL DEVELOPMENT}

In next decade, there are seven challenges for the advancement of distance education, particularly in Asia as it faces the challenge of collaborating with the West, where the movement has been ongoing. These challenges are listed and described below:

\section{The challenge of accreditation and quality assessment}

In next decade, international distance educational accreditation systems need to be developed. Imel (1996) indicated that the overall lack of standards in distance education is an important global issue. In the U.S., there are six major accreditation associations around the nation to evaluate and to accredit traditional education and distance education quality and degrees. In Asia, most counties centralize the control of institutional accreditation. In Taiwan, for example, the Ministry of Education does not recognize distance education degrees from foreign countries. Only the distance education degree from the National Open University (NOU) system in Taiwan is accredited.

It is hard to compare the relative quality of distance educational programs at Western universities and programs at NOU because they are based on different educational missions, evaluation systems, and educational environments. For global educators to have academic exchanges and institutional internationalization of distance educational development, they must be able to share common standards of quality assessment. Therefore, it is important to have an international distance educational accreditation system to unify the evaluation, standards, and quality of distance education. This is a crucial step in the future of international distance education evolution.

\section{The challenge of learning style and educational system differences}

Suzuki (1983) stated that Asian students are stereotypically quiet, docile, and hard working. They are good at following directions but limited in their creativity. In Asia, the student learning style is teachercentered because of traditional Asian culture's social hierarchy. Teachers represent authority, power, and knowledge. It is unethical to challenge, question, or disrespect a teacher's behaviour; therefore, it is natural for Asian students to follow teacher-driven learning styles. 
Distance education is defined as student-centered (Simonson, Smaldino, Albright, \& Zvacek, 2000). This major learning difference influences the level of interaction and other course activities in the classroom. Since the U.S. and other Western counties are leading distance-education development and already have much research and literature to suggest future development, it is important for Asian societies to continue to make a transition into the $3^{\text {rd }}$ distance education generation in order to have more studies and research to define an appropriate learning style for Asian distance learners.

It is possible for the Asian distance educational system to continue to use a teacher-centered distance teaching system if the research and educational systems can agree that this is the best approach for Asian students; however, if the Asian distance educational system can learn from Western distance education experience and literature and make a stylistic transition from teachercentered to student-centered learning, it will be an important advancement and improvement for future international distance educational cooperation.

\section{The challenge of social perspective}

In next decade, educational evaluation standards and processes will shift from input-driven to outputdriven factors. The social attitude in some Asian regulatory agencies toward distance education is still hesitant on the comparative quality of distance education to traditional education. Asian society has long focused on testing outcomes as the standard in quality assessment; student success is evaluated based on national joint college entrance exam scores, and traditional institutions are considered as higher in educational quality than distance institutions because of their assessment processes. In China, in order to overcome this stereotype of distance education, the government started to encourage some of the best institutions to offer distance-learning courses and degrees to students. It made distance-learning degrees become more acceptable in society because of the institutions' reputations.

Evaluation in future quality education development should move from the input-driven concept toward output-driven, which not only evaluates the institution's reputation, faculty/student qualifications, and curriculum design, but also evaluates students' learning outcomes and performances. This will help raise the status of distance education institutions and distance learners; if the distance education students can produce the same levels of learning outcomes as students from traditional settings, they will be as accepted by society as traditional students.

\section{The challenge of language differences}

The leader of the institution that delivers the distance education program to learners with different languages in different nations needs to be aware of the problems of language barriers and its challenges. It is hard to expect students who have different language backgrounds to adapt to a foreign institution's language requirements; however, the spirit of distance education should be defined as an education to all and an education to each. It should provide equal educational accessibility to everyone, anytime, and everywhere.

If language is the major limitation for students to access a quality education or to have increased access to more educational resources, then educators should reconsider this language requirement or policy. Emphasis on English, for example, discriminates against students who can't overcome the language barrier; on the other hand, the student who can speak English will have the privilege to access more educational resources or quality education. It is undeniable that without sufficient 
language skill, students and teachers will have difficulty communicating and having a good quality of interaction. But it is also true that learners who have strong language skills do not always represent positive academic performance and achievement, and students with less than exceptional language skills may be very productive in distance learning programs. Language is important, but it should not be used as the only measure of competence to allow students to participate.

The mode of on-line asynchronous delivery could overcome language if learners have the appropriate translation software and technology to translate the language, or if they have a tutor or mentor. The other possible solution is to establish the same distance program with the same institutional standards and quality but with different languages for delivery.

\section{Challenge of technology economics in distance education development for developing countries}

In the next decade, Asian distance educational system will shift from the $2^{\text {nd }}$ distance education generation into the $3^{\text {rd }}$ generation. Interaction is the key to a quality distance education in this latter stage of development. Reaching a specific level of interaction requires many learning resources and learning environments supported by both learners and distance institutions. Students in developing countries such as China might not have access to full-motion video and audio or an on-line synchronous system because of a lack of economic support for such advanced learning environments.

Currently, the major distance teaching methods of most of open universities in China are one-way telecourses and one-way broadcasting, and insufficient economic assets is the one major limitation to development. The National Open University (NOU) in Taiwan also continues to have the same teaching delivery method as in China; in Taiwan, however, it is not because of a lack of learning resources support -- it is because of a lack of educational vision in a traditional Asian bureaucratic organization.

Whether this technological lag is due to a lack of economic support or the lack of educational vision needed to make a transition to the next generation of interactive capacities, the distance education development in Asia needs to shift toward greater interaction in its distance-learning environments in order to provide quality distance-learning resource to the ever-increasing demand of students.

\section{Challenge to redefine the quality of distance education}

In next the decade, educators should be reconsidering the characteristics of knowledge-based distance-education systems. To evaluate current distance-education development, much research and has focused on which teaching method is the most efficient and which program design can reduce program costs and enhance student learning performance.

There is no doubt that these issues are very important to a knowledge-driven learning system, but teaching method efficiency is a narrow perspective focus in discussions of how to make a quality education system. Education should not consider knowledge delivery only. Besides professional knowledge, students should be able to learn about honor, trust, friendship, love, communication, and personal or group relationships and interactions. The process and content of the learning environment are both important in traditional and distance learning. 
It is hard to define a specific level of quality for process and content. There are essential life skills for everyone. In Taiwan, for example, all traditional institutions are required to ensure that students can develop well in five majors areas: virtue, wisdom, physical strength, group activities, and art. Imagine students who complete their elementary, junior high school, or high school education through distance learning without those outcomes. This would not be a quality education for either traditional or distance education. Distance education has to build success in both cognitive knowledge acquisition and in affective achievements.

When educators consider the quality of distance-education development in the future, it is necessary to consider it from a broad sense of the definition of quality. It will be more difficult and expensive for distance education to provide a good mentor to each student or to reach the specific level of interaction that traditional education does, but it will be very important to reconsider the breadth of education when comparing the quality of a distance learner and a traditional learner.

\section{The challenge for faculty remuneration and administrative support}

It is still a mystery about how to calculate distance education faculty's hourly requirements and salaries fairly and reasonably. The time that faculty, especially senior faculty, must invest in technological training, new curriculum development, and maintaining high levels of interaction with all students is a special consideration in all distance educational systems. Faculty members who invest more time to increase program quality deserve more rewards; it is possible to consider the issue faculty remuneration levels based on the level of program quality and interaction with students.

In Asia's conservative educational environment, it is also very critical to ensure that every faculty who teaches distance learning courses has successfully reached his or her teaching hours and that students did complete and participate in their studying hours. Such educational input evaluation may create distrust and suspicion about whether distance learning instructors and students meet traditional education standards. This could explain why they are still many Asian open universities that adopt radio and telecourse systems as the major modes of delivery, as it is very easy to calculate the faculty teaching hours and student studying hours when using these methods. Convincing a conservative educational system to believe asynchronous on-line distance learning could still have equal or better learning outcomes or learning effectiveness will require more research and study to prove it.

\section{WHAT THEN AFTER KNOWING DIFFERENCES BETWEEN EAST AND WEST EDUCATION?} Cooperative and experiential learning environment could increase active learning and reach toward higher level learning and critical thinking outcomes. The learner-centered concept may not only be good for distance learning, but it is also may be the best approach for increasing learning efficiency and effectiveness in regular classrooms. In distance learning, the learner-centered approach is an important factor to have a successful course/program (Bates, 1995; Moore \& Kearsley, 1996). But this Western perspective is not compatible with many senior teachers in the East. What then after knowing the differences? Asian society may need to develop its own learning theory in distance learning, condemn its current practices, seek a middle-ground in adapting Western ideas, or reject the extension of Western technology. All of these choices are fraught with serious complexities. 
Bennett (1995) indicated that students who have different cultural backgrounds have different ways to learn. Besides learning and teaching style differences, other educational factors have extended from cultural differences in the East and West. Such topics as preferred learning content, learning objectives, teaching activities, learning evaluation, external educational regulations, requirements in credit hours, length of course hours, and degree requirements are examples of factors that vary widely between the East and West.

Asian educational leaders can probably learn much from Western distance educational experience to encourage and threaten Asia to speed up its educational transition. But Asians are not likely to adopt the whole educational system or model from the West. During the next decade, Asian distance educators will likely continue to see a flood of students demanding correspondence education and passive learning. While new interactive information technologies will also become more in the reach of Asia, it is quite likely that change will require careful Asian consideration of the potential of learnercentered philosophy to undo cultural traditions, as well as the performance of many Asian students who have been successful in traditional environments.

If Asian instructors directly adopted WebCT (on-line platform) to support on-line discussion, quizzes, and assignments, but without adjusting the teacher-centered approach, students could continue to be passive and noninteractive. The learning outcomes could be poorer than in traditional face-to-face learning. The educational regulation of the Ministry of Education (MOE) in Taiwan has been hesitant to recognize the educational quality of distance learning, except distance learning degrees from it's national open university, All other distance learning programs are still not accredited by .the MOE in Taiwan, and the maximum distance learning credits are limited to one-third of the total required credits for graduation (MOE, 2004).

Asian and Western distance educators need to continue to examine distance learning theories and principles for use in Asia. Asian social characteristics, such as population, technology access ability, teaching and learning perceptions, learning objective/evaluation, and teaching/learning style differences are issues in a complex interaction that has its own dynamic in change process. As Asia is a conservative society, it takes time for Asian educational transition toward distance learning and life-long learning society, but it is also an important process toward quality assurance development.

Each society has its best educational approach to fit it's own needs and environments, such as to adopt multimedia or virtual learning system in advance technology society, or to adopt correspondence study in undeveloped or developing nations. Each educational system has its advantages. Educational decision makers should not turn necessarily to high technology as always the best concept. If stock could be placed in research findings of no significant difference in learning effectiveness among correspondence, on-line or telecourse media and other modes of delivery (Bates, 1995; Clark, 1994; Moore \& Kearsley, 1996), then it may be that distance educators across the world may need to give pause to becoming part of a frantic effort to use the best of highlyinteractive instructional technology as the norm to reach.

To further global distance learning cooperation, global distance educators should consider flexible and multiple distance learning systems that include different modes of delivery. This will provide true flexible learning environment which including diverse media application for learner to choice. 
Current Asian distance learning is still in the telecourse-driven stage and will have difficulty to use or to practice interactive on-line learning systems from Western society. It seems that on-line learning systems may be a promising direction for Asia to consider; however, it is not all Asian nations who have the resources or human values capital to develop on-line learning environments in a short time. It is predictable that future distance learning system development will combine media and modes of delivery to adjust multi-media applications into global educational development and cooperation in distance learning.

\section{Conclusion}

It is important for educators to be aware of that economics, politics, culture, and educational tradition differences will influence educational applications. The concept of Asian educational bureaucracy and cultural differences could explain the phenomenon of teacher-centered traditions in Asia and hesitation to adopt the learner-centered focus of Western distance learning development in Asia. Educators interested in distance education in Asia will continue to need to pay more attention to the evolving information technologies, the implied instructional theory and methods, and research on learning effectiveness across cultures to get through the transitional process. Distance education is not just a cheap, accessible, second-level educational resource; the quality of distance education should not only meet the mission of educational equity but also satisfy the desire of life-long learning for many people to whom quality education is not currently accessible.

(This paper modified from paper presentation in the 2004 International Conference on Cultural Attitudes towards Technology and Communication (CATaC'04)) and the 2005 Conference on Research in Distance and Adult Learning in Asia and Distance Education in China (CRIDALA/DEC 2005)).

\section{REFERENCES}

Bates, A. W. (1995). Technology, open learning and distance education. New York: Routledge. Bennett, C. (1995) Comprehensive Multicultural Education. (3rd Ed.) Needham Heights, MC: Allyn \& Bacon.

Berge, Z.L. (1998). Barriers to online teaching in post-secondary institutions. Online

Chou, Y. W. (2001). History of Chinese education major themes. Taipei: Chung Cheng.

Clark, R. E. (1994). Media will never influence learning. Educational Technology Research and Development, 42(2), 21-29.

Crosby B. C. (1999). Leadership for global citizenship: Building transnational community. Thousand Oaks, CA : SAGE.

Egan, M. W. \& Gibb, G, S. (1997). Student-centered instruction for the design of telecourses. editor Cyrs. Teaching and learning at a distance: what it takes to effectively design, deliver, and evaluate program.

Imel, S. (1996). Distance Education: Trends and issues alerts. Columbus, Ohio: ERIC clearinghouse on adult, career, and vocational education, the Ohio State University. (ERIC document reproduction service NO. ED 414 446)

Ministry of Education (2004). Procedural rules governing distance learning at the junior college and higher levels. Retrieved April 23, 2004, from: http://www.edu.tw/EDU_WEB/EDU_MGT/ MOECC/EDU1849001/ii7205/dp/wto_edulaw/wto-e18.htm

Moore, M. G., \& Kearsley, G. (1996). Distance education: A systems view. Belmont, CA: Wadsworth Publishing. 
Peterson, M. W. (1997). Using contextual planning to transform institutions. In M. W. Peterson, D. D. Dill, \& L. A. Mets (Eds.), Planning and management for a changing environment: A handbook on redesigning postsecondary institutions. San Francisco, CA: Jossey-Bass.

Shoemaker, J.C.C. (1998). Leadership in continuing and distance education in higher education. Needham Heights, MA: Allyn \& Bacon.

Simonson, M., Smaldino, S., Albright, M., \& Zvacek S. (2000) Teaching and learning at a distant: Foundations of distance education. Uppers addle River, NJ: Prentice Hall.

Suzuki, B.H. (1983). The education of Asian and Pacific Americans: In introductory overview. In Nakanishi, D. \& Nakanishi (Eds.). Education of Asian and Pacific Americans: Historical Perspectives and Prescriptions for the Future. Phoenix, AZ: Oryx Press.

Wu, C. K. (2000). Educational theory. Taipei: National Normal University.

Yukl, G. A. (2002). Leadership in organizations. Upper Saddle River, NJ: Prentice-Hall. 